\title{
Association of serum leptin and adiponectin with anthropomorphic indices of obesity, blood lipids and insulin resistance in a Sub-Saharan African population
}

Clarisse Noël A. Ayina ${ }^{1 *}$, Jean Jacques N. Noubiap ${ }^{2,3}$, Laurent Serge Etoundi Ngoa ${ }^{4}$, Philippe Boudou ${ }^{5}$, Jean François Gautier ${ }^{6,7}$, Michel Karngong Mengnjo ${ }^{8}$, Jean Claude Mbanya ${ }^{8,9,10}$ and Eugene Sobngwi ${ }^{8,9,10}$

\begin{abstract}
Background: There is little data on the metabolic effects of adipokines in sub-Saharan African populations. This study aimed to explore the potential relationship of leptin and adiponectin, with obesity, plasma lipids and insulin resistance in a Cameroonian population.

Methods: We enrolled 167 men and 309 women aged $\geq 18$ years from the general population in Cameroon. Data were collected on waist circumference (WC), body mass index (BMI), waist-to-hip ratio (WHR), body fat (BF\%), fasting blood glucose, plasma lipids, adiponectin, leptin, insulin and homeostasis model for assessment of insulin resistance (HOMA-IR). Pearson's correlation and multiple stepwise linear regression analyses were used to determine correlates of leptin and adiponectin serum levels.
\end{abstract}

Results: The prevalence of obesity was higher in women compared to men $(p<0.0001)$, and Central obesity which is more prevalent particularly in women ( $\mathrm{WC}=42.4 \%$, WHR $=42.3 \%$ ), is almost for $90 \%$ comparable to \%BF (42.7\%). Adiponectin negatively with BMI $(r=-0.294, p<0.0001)$, WC $(r=-0.294, p<0.0001)$, \%BF $(r=-0.122, p=0.028)$, WHR $(r=-0.143, p=0.009)$, triglycerides $(r=-0.141, p=0.011)$, HOMA-IR $(r=-0.145, p=0.027)$ and insulin $(r=-0.130$, $p=0.048)$. Leptin positively correlated with BMI $(r=0.628)$, WC $(r=0.530), \mathrm{BF} \%(r=0.720)$, (all $p<0.0001)$; with $\operatorname{DBP}(r=0.112, p=0.043)$, total cholesterol $(r=0.324, p<0.0001)$, LDL-cholesterol $(r=0.298, p<0.0001)$, insulin $(r=0.320, p<0.001$ and HOMA-IR $(r=0.272, p<0.0001)$.

In multiple stepwise regression analysis, adiponectin was negatively associated with $W C(\beta=-0.38, p=0.001)$ and $\mathrm{BF} \%(\beta=0.33, p<0.0001)$, while leptin was positively associated with $\mathrm{BF} \%(\beta=0.60, p<0.0001)$, total cholesterol $(\beta=0.11, p=0.02)$ and HOMA-IR $(\beta=0.11, p=0.02)$. When controlled for gender, HOMA-IR was found significantly associated to adiponectin $(\beta=0.13, p=0.046$ ), but not $B F \%$, while the association previously found between leptin and HOMA-IR disappeared; BMI and WC were significantly associated with leptin ( $\beta=0.18, p=0.04 \& \beta=0.19, p=0.02$ respectively).

(Continued on next page)

\footnotetext{
* Correspondence: c_ayina@yahoo.fr

${ }^{1}$ Department of Animal Science, Faculty of Science, University of Douala,

Douala, Cameroon

Full list of author information is available at the end of the article
} 
(Continued from previous page)

Conclusion: This study, which includes a population who was not receiving potentially confounding medications, confirms the associations previously observed of adiponectin with reduced adiposity especially central adiposity and improved insulin sensitivity. Confirmatory associations were also observed between leptin and obesity, blood lipids and insulin resistance for the first time in an African population. Gender was significant covariate interacting with insulin sensitivity/insulin resistance and obesity indexes associations in this population.

Keywords: Adipokines, Adiponectin, Leptin, Blood lipids, Insulin resistance, Insulin sensitivity, Obesity indices

\section{Background}

Africa is experiencing a surge in obesity prevalence and related morbidity and mortality within the context of one of the most rapid epidemiological transition in the world history [1]. Insulin resistance and consequently type 2 diabetes mellitus are major metabolic sequelae of obesity. Adipose tissue has been identified as a link between obesity and insulin resistance [2].

Adipose tissue is now regarded as not just a purely inert body compartment for excess energy storage, but rather as an active endocrine and paracrine organ, secreting a large number of hormones, cytokines and growth factors, collectively called adipokines [3]. Some of them are synthesized exclusively or predominantly by adipocytes (e.g., adiponectin, leptin), while others originate from other sources as well (e.g., resistin, chemerin, proinflammatory cytokines) [4]. Adiponectin and leptin are of particular interest because of their role in the regulation of various physiological processes, including insulin responsiveness, glucose and lipid metabolism, as well as endothelial function, inflammatory response and cytokine signaling [4].

Indeed, there is evidence that adiposity, as measured through body mass index (BMI), and insulin resistance are associated with circulating levels of leptin and adiponectin; leptin has a positive association with adiposity and insulin resistance whereas the converse correlation exists between adiponectin and adiposity and insulin resistance [5-7]. Furthermore, there has been recent interest in the leptin-to-adiponectin ratio (LAR) as a novel predictor of cardio-metabolic and other chronic disease outcomes. This ratio has been shown to be associated with insulin resistance [8,9], metabolic syndrome [10], carotid intima-media thickness [11], "at-risk phenotype" in young severely obese patients [9], and chronic kidney disease [12], among others.

Adiponectin and leptin circulate in lower concentrations in healthy male compare to female, and is mainly attributed to lower amounts of hexameric High Molecular Weight (HMW) form of adiponectin [13, 14], and to adipose tissue for leptin [15]. Like many other metabolic hormones, adiponectin, especially its HMW form, is regulated by the biological clock showing circadian rhythms with a nocturnal reduction [16]; yet, it's plasma concentration does not depend on fasting status, show only a limited intra-personal variation over time. On the other hand, leptin shows a circadian variation with a moderate oscillation with their secretion being influenced by regularly eating cycles [17].

Adiponectin and leptin levels vary across ethnic populations. Higher mean levels of leptin and lower mean levels of adiponectin have been reported in AfricanAmericans as compared to subjects of Caucasian ethnicity [18-21]. However, studies that have investigated the role of these adipokines in various diseases among African populations are very scarce. Circulating adiponectin levels were significantly associated with measures of obesity, serum lipids, and insulin resistance in a study on West African population [22]. Circulating Adiponectin was reported to be associated with renal function independent of age and serum lipids in West Africans. According to their findings, the authors suggest that adiponectin may have clinical utility as a biomarker of renal function [23]. A study conducted on urban South African blacks with and without coronary artery disease (CAD) revealed that leptin differentiated between CAD patients with and without metabolic syndrome and determined metabolic syndrome status in women and men [24]. The current study aimed to investigate the potential relationship between leptin and adiponectin, and obesity, blood lipids and insulin resistance in the Cameroonian population. We were particularly interested in determining whose of BMI, waist circumference (WC), waist-to-hip ratio (WHR) and percent body fat (BF \%) as surrogates of adiposity, better correlate with leptin and adiponectin plasma levels. Data will contribute to a better understanding of the metabolic effects of these cytokines and their potential as therapeutic targets and predictor of cardio-metabolic outcomes in sub-Saharan Africans.

\section{Methods}

\section{Study population}

This is a cross-sectional study conducted in May 2010 in Douala and Edea, two urban cities of the Littoral region of Cameroon. The study population consisted of individuals 
of both genders aged $\geq 18$ years from the general population, who accepted to participate in the study after an invitation through radio announcements. Pregnant and breast-feeding women, as well as subjects with serious chronic illness, or ongoing or recent $(<10$ days) acute illness, or those taking any current medication were excluded from the study. After applying the exclusion criteria, 476 participants were included in the study.

\section{Data collection}

For each subject, weight was measured in light clothes with a Seca Scale balance to the nearest $0.1 \mathrm{~kg}$, height with a calibrated stadiometer, waist circumference (WC) at midway between the lowest rib and the iliac crest and hip circumference at the outermost points of the greater trochanters to the nearest $0.5 \mathrm{~cm}$ and waist-to-hip ratio (WHR) as waist circumference divided by hip circumference. Body mass index (BMI) was calculated using the Quetelet's formula as weight (in $\mathrm{kg}$ ) divided by height $\left(\right.$ in $\mathrm{m}^{2}$ ). We measured resting blood pressures twice using standardized procedures with the participant in a seated position, and after at least 10 min rest with a validated automated blood pressure measuring device, the Omron HEM-757 (Omron Corporation, Tokyo, Japan). The mean of two measures performed at least three minutes apart was used for all analyses.

Percentage body fat (\%BF) was measured by bioelectric impedance analysis using the OMRON BF 302 (OMRON Matsusaka Co., Tokyo, Japan). After 8-12 h overnight fast, blood glucose was measured between 7 and 10 am using the Accu-Chek ${ }^{\circ}$ Compact Plus glucometer (F. Hoffmann-La Roche AG, Basel, Switzerland) on total fresh capillary blood samples, and venous blood samples were obtained from an antecubital vein. Serum was then separated and stored at $-20{ }^{\circ} \mathrm{C}$ for lipid measurements and at $-80{ }^{\circ} \mathrm{C}$ for further biochemical analysis. Serum lipids were analyzed within one week after the collection. Serum cholesterol (TC) (cholesterol oxidase phenol 4-amino antipyrene peroxidase method), serum triglycerides (TG) (glycerol phosphatase oxidase - phenol4-amino antipyrene peroxidase method), and high-density lipoprotein -cholesterol (HDL-c) (cholesterol oxidase phenol4-amino antipyrene peroxidase method) were measured on a spectrophotometer (UV Mini 1240) using Chronolab kits (Chronolab Systems, Barcelona, Spain). Low-density lipoprotein -cholesterol (LDL-c) was calculated using the Friedwald's formula [25]. Insulin levels were measured using an electrochemiluminescence immunoassay (Roche Diagnostics, Indianapolis, USA), while serum leptin and adiponectin were measured measured by Radio Immuno Assay (RIA) using Linco Research kits (Linco Research Inc., St Charles, Missouri, USA) with the following characteristics: Adiponectin assay coefficient of variation $(\mathrm{CV}) \leq$
$10 \%$; detection limit of $2 \mathrm{ng} / \mathrm{ml}$ for $100 \mu \mathrm{l}$ sample size; a linearity range of $500 \mathrm{ng} / \mathrm{ml}$ for $100 \mu \mathrm{l}$ sample size. Leptin assay's coefficient of variation $\leq 10 \%$ (intra-assay's $\mathrm{CV} \leq 8.3 \%$ and inter assay's $\mathrm{CV} \leq 6.2 \%$ ); a detection limit of $0.5 \mathrm{ng} / \mathrm{ml}$ for $100 \mu \mathrm{l}$ sample size; a linearity range of $100 \mathrm{ng} / \mathrm{ml}$ for $100 \mu \mathrm{l}$ sample size. Anthropometrical and biochemical measurements were made once on each participant.

Homeostasis Model Assessment of Insulin Resistance $($ HOMA-IR) as HOMA - IR $=($ Fasting insulin $\times$ Fasting blood glucose) $\div 22.5$.

\section{Definition of anthropomorphic indices of obesity}

According to the World Health Organization guidelines, obesity was defined as BMI $\geq 30 \mathrm{~kg} / \mathrm{m}^{2}$ [26], WC $>94 \mathrm{~cm}$ in men and $>80 \mathrm{~cm}$ in women, WHR $\geq 0.90$ in men and $\geq 0.85$ in women [27]. The BF\% cutoffs chosen to define obesity were the values most frequently cited by international scientific literature: $\mathrm{BF} \% \geq 25$ for men and $\geq 35$ for women [28].

\section{Statistical analysis}

Data were coded, entered and analyzed using the Statistical Package for Social Science (SPSS) version 20.0 for Windows (IBM Corp. Released 2011. IBM SPSS Statistics for Windows, Version 20.0. Armonk, NY: IBM Corp.). The distribution pattern of the variables was checked. Normally distributed variables are expressed as mean with standard deviation (SD). Skewed variables are reported as median (interquartile range). Skewed variables were log transformed. The independent sample $t$ test was used to compare clinical and biological parameters between men and women. Spearman's correlation and multiple stepwise linear regression analyses were used to determine correlates of leptin and adiponectin serum levels. Multiple stepwise regression analysis included adiponectin and leptin as dependent variables and on one hand the factors which $p<0.05$ from the bivariate correlation. These are $\mathrm{BMI}, \mathrm{WC}, \mathrm{BF} \%$, WHR, TG and HOMA-IR for adiponectin, and BMI, WC, BF\%, TC, TG, LDL-c and HOMA-IR for leptin. WHR was removed from the final model for adiponectin because it interacts with WC as central obesity index and negative impact on the model. Each model was controlled for age and gender. Statistical tests are two tailed. A $p$ value $<0.05$ was considered statistically significant.

\section{Ethical considerations}

This study was performed in accordance with the guidelines of the Helsinki Declaration and was approved by the National Ethics Committee for Human Health Research and by the Ministry of Public Health of Cameroon. Written informed consent was obtained from all participants. 


\section{Results}

A total of 476 subjects (167 men and 309 women) were enrolled in the study. The median age (interquartile) was 55.0 (23.6) for men and 50.0 (20.0) for women $(p<0.05)$. WHR, SBP and DBP were significantly higher in men $(p<0.05$ respectively). Triglycerides, LDL-c024), insulin, adiponectin, leptin, and HOMA-IR were significantly higher in women $(p<0.05$ respectively) (Table 1).

\section{Prevalence of obesity using the different anthropomorphic indexes}

The prevalence of obesity using the different obesity indexes was significantly higher in women than in men (all $p<0.001$ ). Men, had a higher prevalence of BF\% (11.8 \%), BMI and WC showed quasi-equal prevalence rates $(7.4 \%$ \& $7.7 \%$ respectively); and a low WHR prevalence (5.4\%). In women, WC, WHR and $\mathrm{BF} \%$ had the higher prevalence than men (42.7\%, $42.3 \%$ and $42.7 \%$ respectively) and lowest prevalence of obesity BMI (425.5 \%) (Fig. 1). Central obesity measured with WC and WHR seems to reflect body fat better than general obesity measured with BMI in this population.

Table 1 Clinical and metabolic characteristics of the study population

\begin{tabular}{|c|c|c|c|}
\hline & Men $(n=167)$ & Women $(n=309)$ & $p$ value \\
\hline Age & $55(23)$ & $50(20)$ & $<0.0001$ \\
\hline Weight (kg) & $71.00(23.00)$ & $70.00(25.00)$ & 0.984 \\
\hline Height (m) & $1.70(0.20)$ & $1.60(0.10)$ & $<0.0001$ \\
\hline BMI $\left(\mathrm{kg} / \mathrm{m}^{2}\right)$ & $25.30(6.30)$ & $28.00(6.60)$ & $<0.0001$ \\
\hline WC $(\mathrm{cm})$ & $91.04 \pm 12.6$ & $93.58 \pm 14.0)$ & 0.091 \\
\hline WHR $(\mathrm{cm})$ & $0.91(0.09)$ & $0.87(0.09)$ & $<0.0001$ \\
\hline $\mathrm{BF}(\%)$ & $22.90(8.62)$ & $34.00(10.42)$ & $<0.0001$ \\
\hline $\mathrm{SBP}(\mathrm{mm} \mathrm{Hg})$ & $137(37)$ & $1128(33)$ & $<0.0001$ \\
\hline $\mathrm{DBP}(\mathrm{mm} \mathrm{Hg})$ & $86(21)$ & $82(20)$ & 0.006 \\
\hline Blood glucose (mmol/L) & $5.0(1.10)$ & $4.80(1.15)$ & 0.204 \\
\hline Total Cholesterol (mmol/L) & $4.14(1.07)$ & $4.45(1.16)$ & 0.05 \\
\hline Triglycerides (mmol/L) & $1.20(0.45)$ & $1.26(0.35)$ & 0.024 \\
\hline LDL-c (mmol/L) & $1.48(0.97)$ & $1.78(1.17)$ & 0.031 \\
\hline HDL-c (mmol/L) & $2.13(0.99)$ & $2.14(0.91)$ & 0.763 \\
\hline Insulin $(\mu \mathrm{U} / \mathrm{mL})$ & $2.14(2.16)$ & $2.73(2.47)$ & 0.020 \\
\hline HOMA-IR & $8.64(0.25)$ & $11.05(11.13)$ & 0.031 \\
\hline Adiponectin $(\mu \mathrm{g} / \mathrm{mL})$ & $7.65(5.55)$ & $10.75(8.90)$ & 0.038 \\
\hline Leptin (ng/mL) & $4.80(6.20)$ & $18.50(24.40)$ & $<0.0001$ \\
\hline
\end{tabular}

WC Values are means (standard deviation); except for WC, values are Median (Interquartile Range)

$W C$ waist circumference, $B F \%$ body fat percentage, $B M I$ body mass index, WHR waist-hip ratio, SBP systolic blood pressure, $D B P$ diastolic blood pressure, $L D L-C$ low density lipoprotein-cholesterol, $H D L-c$ high density lipoprotein-cholesterol, HOMA-IR homeostasis model assessment of insulin resistance
Correlations between adipokines and anthropomorphic indexes of obesity, blood pressure, blood lipids and insulin resistance

As shown in Table 2, adiponectin positively and significantly correlated with age $(r=0.200, p<0.0001)$ and negatively correlated with BMI $(r=-0.294, p<0.0001)$, WC $(r=-0.294, p<0.0001)$, WHR $(r=-0.143, p=0.009$ and BF\% $(r=-0.122, p=0.028)$. There was no significant correlation between adiponectin and blood pressure. On the other hand, adiponectin correlated negatively with triglycerides $(r=-0.141, p=0.011)$, insulin $(r=-0.130, p=$ $0.048)$ and HOMA-IR $(r=-0.145, p=0.027)$.

There was a significantly positive correlation between leptin and BMI $(r=0.628, p<0.0001)$, WC $(r=0.530, p<0.0001)$ and BF\% $(r=0.729, p<0.0001)$. Leptin also positively correlated with DBP $(r=0.112$, $p=0.043)$, total cholesterol $(r=0.324, p<0.0001)$, LDL-cholesterol $(r=0.298, p<0.0001)$, Triglycerides $(r=0.148, \quad p=0.007)$, insulin $(r=0.320, \quad p<0.0001)$ and HOMA-IR $(r=0.273, p<0.0001)$.

In multiple stepwise regression analysis, WC was negatively associated with adiponectin $(\beta=-0.38, p<$ 0.0001, CI: $-0.009--0.0004)$ and remained unchanged after control for age and gender; a model that explained $26 \%$ of the variance of adiponectin levels. WC is then the index of obesity that better predict adiponectin levels in this population. The positive association between $\mathrm{BF} \%$ and adiponectin $(\beta=0.33, p<0.0001, \mathrm{CI}: 0.004-0.013)$ was weakened by age and strongly dependent of gender. HOMA-IR was negatively associated with adiponection when controlled for gender $(\beta=-0.125, p=0.045, \mathrm{CI}$ : $-0.081-0.000)$. That association was significant $(\mathrm{p}=$ 0.05 ) when age was added in the model. Age may impact on the relation between insulin resistance and adiponectin in this population. Age and gender were both significant covariates positively associated with adiponectin $(\beta=0.24, \quad p<0.0001, \quad$ CI: $0.002-$ $0.007 \& \beta=0.29, p<0.0001, \mathrm{CI}: 0.09-0.22$ respectively) (Table 3, Fig. 2).

Leptin was positively associated with BF\% $(\beta=0.60$, $p<0.0001$, CI: $0.05-0.08)$, TC $(\beta=0.11, p=0.02)$ when controlled for age and gender, a model that explain $68 \%$ of leptin levels. When controlling for gender only, BMI and WC were both positively associated with leptin $(p=0.04 \& p=0.02$ respectively). Age may strongly influence the relation between BMI and leptin. Except for BF\%, WC was the obesity index significantly associated to leptin after control for age and gender. The association of HOMA-IR with leptin $(\beta=0.11, p=0.02 \mathrm{CI}: 0.0-0.29)$ was dependent of gender, although reinforcement of age. Age and gender were both significant covariates positively associated to leptin $(p=0.001, p<0.0001$ respectively) (Table 4, Fig. 3). 


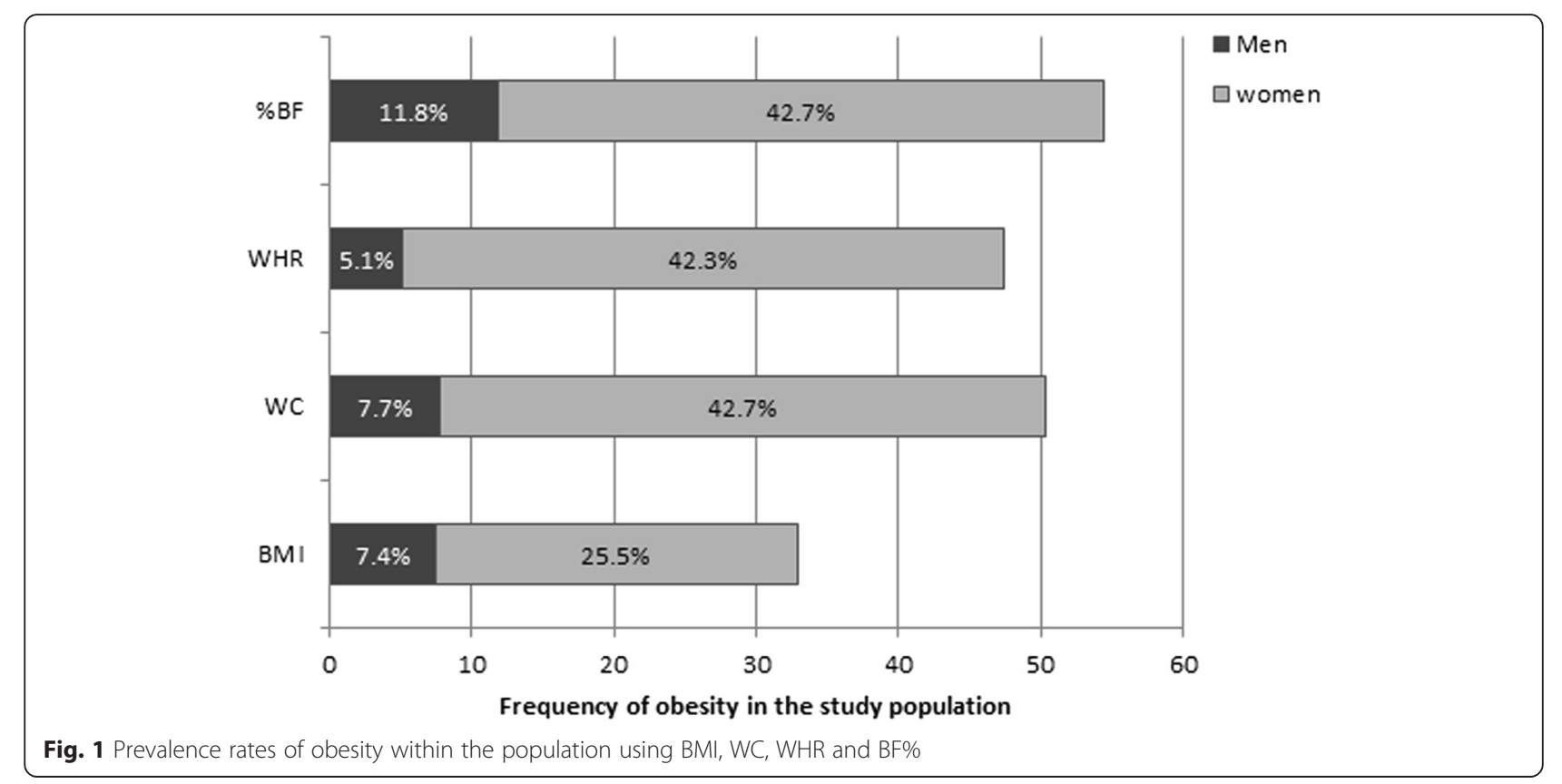

\section{Discussion}

During the last decade, several studies demonstrated the important role of adiponectin and leptin in the regulation of various physiological processes, including insulin responsiveness, glucose and lipid metabolism, as well as endothelial function, inflammatory response and cytokine signaling [4]. These adipokines have therefore been postulated to be strong predictors of cardiometabolic

Table 2 Spearman's correlation coefficients of adiponectin and leptin

\begin{tabular}{|c|c|c|c|c|}
\hline & \multicolumn{2}{|c|}{ Adiponectin } & \multicolumn{2}{|l|}{ Leptin } \\
\hline & $r$ & $p$ & $r$ & $p$ \\
\hline$\overline{\text { Age }}$ & 0.200 & $<0.0001$ & -0.115 & 0.038 \\
\hline $\mathrm{BMI}$ & -0.294 & $<0.0001$ & 0.628 & $<0.0001$ \\
\hline WC & -0.294 & $<0.0001$ & 0.530 & $<0.0001$ \\
\hline WHR & -0.143 & 0.009 & -0.029 & 0.599 \\
\hline $\mathrm{BF} \%$ & -0.122 & 0.028 & 0.729 & $<0.0001$ \\
\hline SBP & 0.009 & 0.869 & 0.026 & 0.643 \\
\hline DBP & -0.009 & 0.871 & 0.112 & 0.043 \\
\hline TC & -0.070 & 0.207 & 0.324 & $<0.0001$ \\
\hline TG & -0.141 & 0.011 & 0.148 & 0.007 \\
\hline $\mathrm{HDL}-\mathrm{C}$ & 0.102 & 0.064 & -0.022 & 0.685 \\
\hline LDL-C & -0.061 & 0.279 & 0.298 & $<0.0001$ \\
\hline Insulin & -0.130 & 0.048 & 0.320 & $<0.0001$ \\
\hline HOMA-IR & -0.145 & 0.027 & 0.273 & $<0.0001$ \\
\hline
\end{tabular}

WC waist circumference, $B F \%$ body fat percentage, $B M I$ body mass index, WHR waist-hip ratio, $S B P$ systolic blood pressure, $D B P$ diastolic blood pressure, $T C$ total cholesterol, TG triglycerides, LDL-c low density lipoprotein-cholesterol, $H D L-c$ high density lipoprotein-cholesterol, HOMA-IR homeostasis model assessment of insulin resistance and other chronic disease outcomes [5-12]. Much more, adiponectin has been identified as a therapeutic target and several strategies have been suggested for increasing its favorable effects [29-31]. This study was designed to explore the relationships of leptin and adiponectin with various anthropometric indexes of obesity, blood lipids and insulin resistance among a Cameroonian population.

We found that plasma adiponectin concentrations are positively correlated to age, and negatively related with BMI, WC, BF\%, WHR, triglycerides, insulin levels, and HOMA-IR. In contrast, leptin plasma levels positively correlated with $\mathrm{BMI}, \mathrm{WC}, \mathrm{BF} \%, \mathrm{DBP}$, total cholesterol, triglycerides, LDL-cholesterol and insulin levels, and HOMA-IR. The finding of an inverse relationship between $\mathrm{BMI}, \mathrm{WC}$ and $\mathrm{BF} \%$ is similar to previous reports in Americans [32], Japanese subjects [33], Pima Indians and Caucasians [34]. A similar association was also found among African-American in the Multi-Ethnic Study of Atherosclerosis (MESA) [35]. In a previous study, we also found that adiponectin was inversely correlated with waist circumference in apparently healthy Cameroonians [36]. This negative correlation between adiponectin and these surrogates of obesity may be due to the fact that adiponectin gene expression is downregulated in obesity and its related pathology [12, 32]. Furthermore, we found that except for BMI, WC exhibits the stronger negative correlation with adiponectin levels. Yet, the responsibility of subcutaneous or visceral fat in this association is discussed [37, 38]. This result is in accordance with the observation that cultured adipocytes derived from the intra-abdominal fat depot secrete 
Table 3 Multiple regression analysis with adiponectin as dependent variable

\begin{tabular}{|c|c|c|c|c|c|c|c|c|c|c|c|c|}
\hline & \multicolumn{3}{|c|}{$\begin{array}{l}\text { No control for age } \\
\text { nor gender }\left(R^{2}=0.19\right)\end{array}$} & \multicolumn{3}{|c|}{$\begin{array}{l}\text { Control for } \\
\text { age }\left(R^{2}=0.21\right)\end{array}$} & \multicolumn{3}{|c|}{$\begin{array}{l}\text { Control for } \\
\text { gender }\left(R^{2}=0.20\right)\end{array}$} & \multicolumn{3}{|c|}{$\begin{array}{l}\text { Control for gender } \\
\text { and age }\left(R^{2}=0.26\right)\end{array}$} \\
\hline & Beta & $p$ & $95 \% \mathrm{Cl}$ & Beta & $p$ & $95 \% \mathrm{Cl}$ & Beta & $p$ & $95 \% \mathrm{Cl}$ & Beta & $p$ & $95 \% \mathrm{Cl}$ \\
\hline$\overline{\text { Age }}$ & & & & 0.17 & 0.01 & $0.001-0.010$ & & & & 0.24 & $<0.0001$ & $0.002-0.007$ \\
\hline Sex & & & & & & & 0.25 & $<0.0001$ & $0.06-0.19$ & 0.29 & $<0.0001$ & $0.09-0.22$ \\
\hline $\mathrm{BMl}$ & -0.21 & 0.10 & $-0.59-0.05$ & -0.13 & 0.39 & $-0.54-0.21$ & -0.15 & 0.19 & $-0.50-0.10$ & 0.06 & 0.70 & $-0.30-0.46$ \\
\hline WC & -0.38 & 0.001 & $-0.01--0.002$ & -0.53 & $<0.0001$ & $-0.18-0.59$ & -0.32 & $<0.0001$ & $-0.008--0.08$ & -0.37 & $<0.0001$ & $-0.009--0.004$ \\
\hline $\mathrm{BF} \%$ & 0.33 & $<0.0001$ & $0.004-0.01$ & 0.21 & 0.01 & $0.002-0.01$ & 0.17 & 0.18 & $-0.002-0.01$ & -0.10 & 0.38 & $-0.01-0.003$ \\
\hline TG & -0.09 & 0.16 & $-0.33-0.05$ & -0.06 & 0.32 & $-0.28-0.09$ & -0.07 & 0.25 & $-0.30-0.08$ & -0.08 & 0.20 & $-0.30-0.6$ \\
\hline HOMA-IR & -0.11 & 0.96 & $-0.08-0.01$ & -0.10 & 0.13 & $-0.07-0.01$ & -0.13 & 0.046 & $-0.08-0.000$ & -0.12 & 0.05 & $-0.08-0.000$ \\
\hline
\end{tabular}

Cl Confidence Interval, BMI body mass index, WC waist circumference, BF\% body fat percentage, TG triglycerides, HOMA-IR homeostasis model assessment of insulin resistance

adiponectin more actively than subcutaneous fat derived adipocytes [39]. In this study, WC was the only obesity index significantly associated to adiponectin when controlled for age and gender. This finding confirms the conclusions that WC is the obesity index the better correlate with obesity related diseases [40].

It has been demonstrated that plasma adiponectin concentrations correlate negatively with insulin resistance (or correlate positively with insulin sensitivity) and fasting plasma insulin concentrations [32, 34, 41-44]. Likewise, we found that adiponectin levels are negatively associated with plasma insulin level and HOMA-IR; however, these associations seem to depend on gender in this population. These findings support the notion that adiponectin concentrations could modulate insulin action. Indeed, of the adipokines, adiponectin may be the most biologically active in improving insulin sensitivity. Adiponectin is believed to improve insulin sensitivity by binding to its receptors including AdipoR1 which is expressed primarily in skeletal muscle, and AdipoR2 which is expressed most abundantly in the liver. These receptors mediate the adiponectin-induced increase in glucose uptake in muscle and the decrease in glucose production by liver (hepatic gluconeogenesis), respectively $[45,46]$. Because of this important role on insulin sensitivity, adiponectin is currently one of the strongest biochemical predictors of type 2 diabetes mellitus [47]. However, sex hormons can modify the expression and activities of PPAR $\gamma$ and its downstream adipokines [48].

Besides its action as an insulin sensitizer, adiponectin exerts an anti-atherogenic activity by increasing fatty acid uptake and oxidation through the activation of AMP activated protein kinase (AMPK), p38-mitogenactivated protein kinase (MAPK), and peroxisome proliferator-activated receptor gamma (PPAR $\alpha$ ) pathways [49-52]. We found that plasma adiponectin concentrations are negatively correlated with circulating triglycerides concentrations. These findings are in line with previous studies which reported that serum levels of lipids and lipoproteins (triglycerides, LDLcholesterol, apolipoprotein A1 and apolipoprotein B) were significantly increased but HDL-C was decreased with decreasing adiponectin levels. It is assumed that the association of adiponectin with lower triglyceride concentrations is secondary to its insulin-sensitizing properties [53].

Leptin has been identified as an important protein involved in the weight regulation system, and the absence of leptin leads to increased appetite and decreased energy expenditure and subsequently obesity [54]. The interaction between leptin and fat mass and obesityassociated (FTO) gene expression is a major mechanistic pathway underlying the role of leptin in the regulation of body-weigh [4]. Interestingly, this study confirms the positive and strong association found between serum leptin levels and percentage body fat. WC and BMI were also found associated to leptin after control for gender. This association of leptin with obesity has been previously demonstrated in a multi-ethnic population including African-Americans [35], as well as in subjects with various obesity-related pathologies such as in type 2 diabetes $[44,55,56]$. Furthermore, we found that leptin plasma concentrations also positively correlated with plasma insulin concentrations and HOMA-IR thus insulin resistance. These findings have been reported in previous studies in type 2 diabetes patients $[44,55,56]$. In fact, hyperinsulinemia and insulin resistance were reported to induce hyperleptinemia through increased adiposity [53, 54]. Beside, the positive correlation between leptin and DBP in this study is in accordance with observational data associating leptin with cardiovascular disease [4], as well as the positive association found with plasma total cholesterol. These associations of leptin with raised blood pressure and pro-atherogenic blood lipids, along with its role in insulin resistance and endothelial dysfunction, in diabetes and hypertension onset, and its pro-inflammatory activity are the major mechanisms through which leptin triggers cardiovascular diseases [4]. 

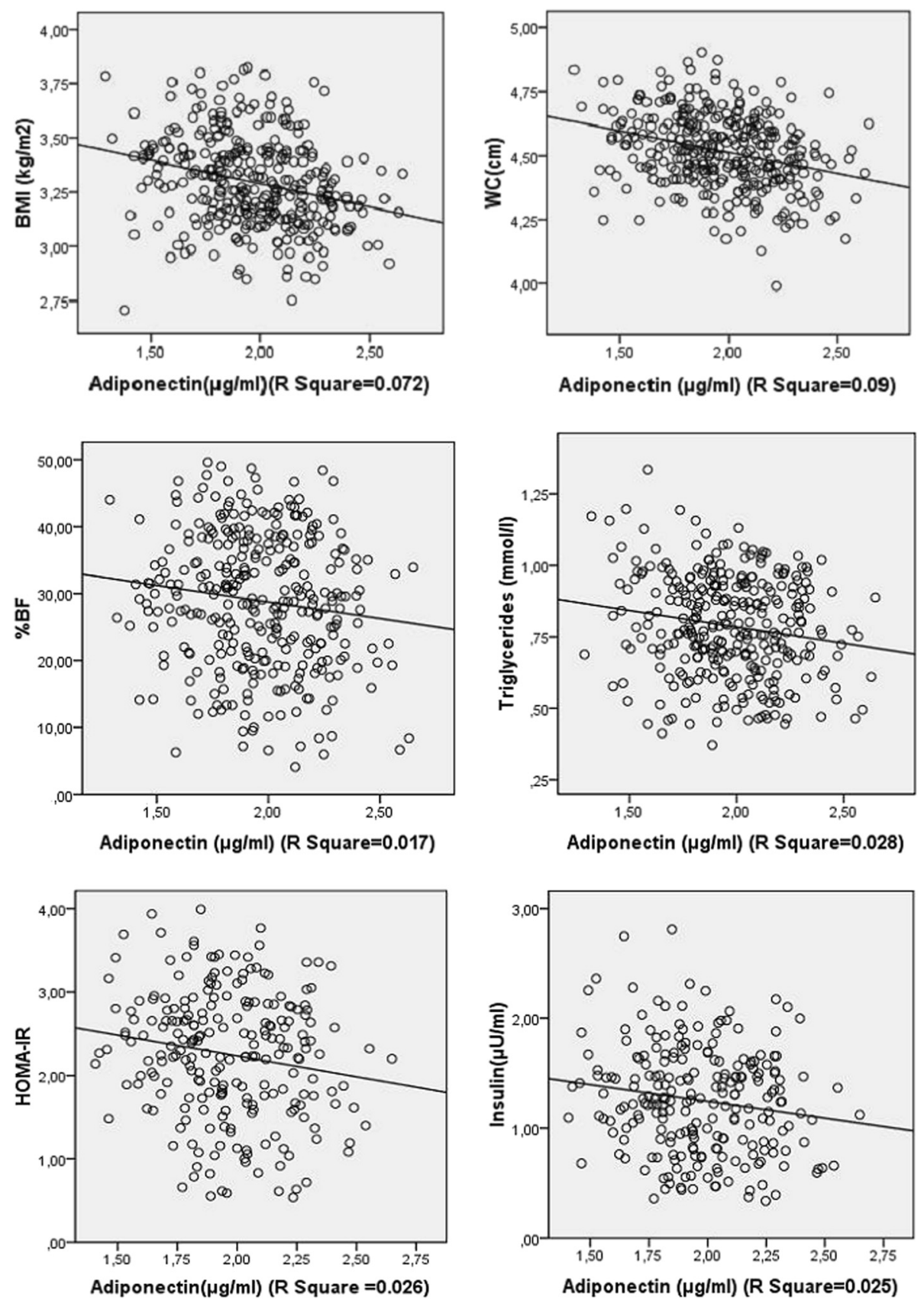

Fig. 2 Linear regression presenting the associations of adiponectin with BMI, WC, BF\%, triglycerides, insulin and HOMA-IR

Our study has a principal strength that this population was not receiving potentially confounding medications during the investigation. Nevertheless, this study has three main limitations. First, its cross-sectional design prevented us from identifying cause-and-effect associations between leptin and adiponectin, and blood lipids, obesity and insulin resistance. Secondly, we used HOMA-IR to evaluate insulin sensitivity rather than gold-standard methods such as the hyperinsulinemic euglycemic clamp and the frequently sampled- intravenous glucose tolerance test which, however, would have been significantly very difficult to perform in such a population-based study in a resource-limited setting. Despite these shortcomings our study is one the very few to report on the relationship of leptin and adiponectin with lipid profile, anthropomorphic indexes of obesity and insulin sensitivity among subjects of African ancestry. Thirdly, in this study we used a commercially available RIA method (Linco Research Inc.) which measures only total adiponectin, though recent 
Table 4 Multiple regression analysis with leptin as dependent variable

\begin{tabular}{|c|c|c|c|c|c|c|c|c|c|c|c|c|}
\hline & \multicolumn{3}{|c|}{ No control for age nor gender $\left(R^{2}=0.60\right)$} & \multicolumn{3}{|c|}{ Control for age $\left(R^{2}=0.65\right)$} & \multicolumn{3}{|c|}{ Control for gender $\left(R^{2}=0.66\right)$} & \multicolumn{3}{|c|}{ Control for gender and age $\left(R^{2}=0.68\right)$} \\
\hline & Beta & $p$ & $95 \% \mathrm{Cl}$ & Beta & $p$ & $95 \% \mathrm{Cl}$ & Beta & $p$ & $95 \% \mathrm{Cl}$ & Beta & $p$ & $95 \% \mathrm{Cl}$ \\
\hline Age & & & & -0.23 & $<0.0001$ & $-0.02--0.01$ & & & & -0.16 & 0.001 & $-0.02--0.005$ \\
\hline Sex & & & & & & & 0.35 & $<0.0001$ & $0.51-1.01$ & 0.24 & $<0.0001$ & $0.26-0.81$ \\
\hline $\mathrm{BMl}$ & 0.13 & 0.06 & $-0.03-0.12$ & -0.11 & 0.28 & $-0.75-0.50$ & 0.18 & 0.04 & $0.03-0.09$ & -0.02 & 0.99 & $-0.14-0.12$ \\
\hline WC & $-0,02$ & 0,81 & $-0,04-0,01$ & 0.07 & 0.22 & $-0.02-0.002$ & 0.19 & 0.02 & $0.01-0.03$ & 0.22 & 0.001 & $0.06-0.07$ \\
\hline $\mathrm{BF} \%$ & 0.60 & $<0.0001$ & $0.05-0.08$ & 0.75 & $<0.0001$ & $0.07-0.09$ & 0.29 & 0.001 & $0.01-0.05$ & 0.48 & $<0.0001$ & $0.03-0.07$ \\
\hline DBP & $-0,01$ & 0,91 & $-0,62-0,55$ & -0.04 & 0.35 & $-0.29-0.81$ & 0.06 & 0.19 & $-0.18-0.92$ & 0.05 & 0.23 & $-0.21-0.88$ \\
\hline TC & 0.11 & 0.02 & $0.07-0.84$ & 0.10 & 0.02 & $0.06-0.79$ & 0.12 & 0.01 & $0.13-0.85$ & 0.12 & 0.007 & $0.14-0.85$ \\
\hline TG & $-0,04$ & 0,35 & $-0,87-0,31$ & -0.06 & 0.14 & $-0.95-0.14$ & -0.05 & 0.22 & $-0.89-0.21$ & -0.07 & 0.09 & $-0.97-0.08$ \\
\hline LDL-C & $-0,07$ & 0,21 & $-0,16-0,04$ & -0.03 & 0.53 & $-0.12-0.06$ & -0.03 & 0.56 & $-0.13-0.07$ & -0.01 & 0.91 & $-0.10-0.09$ \\
\hline HOMA-IR & 0.11 & 0.02 & $0.02-0.29$ & 0.11 & 0.015 & $0.03-0.28$ & 0.07 & 0.12 & $0.02-0.22$ & 0.09 & 0.03 & $-0.01-0.26$ \\
\hline
\end{tabular}

CI Confidence Interval, WC waist circumference, BF\% body fat percentage, BMI body mass index, TC total cholesterol, TG triglycerides, LDL-c low density lipoprotein-cholesterol, HOMA-IR homeostasis model assessment of insulin resistance 

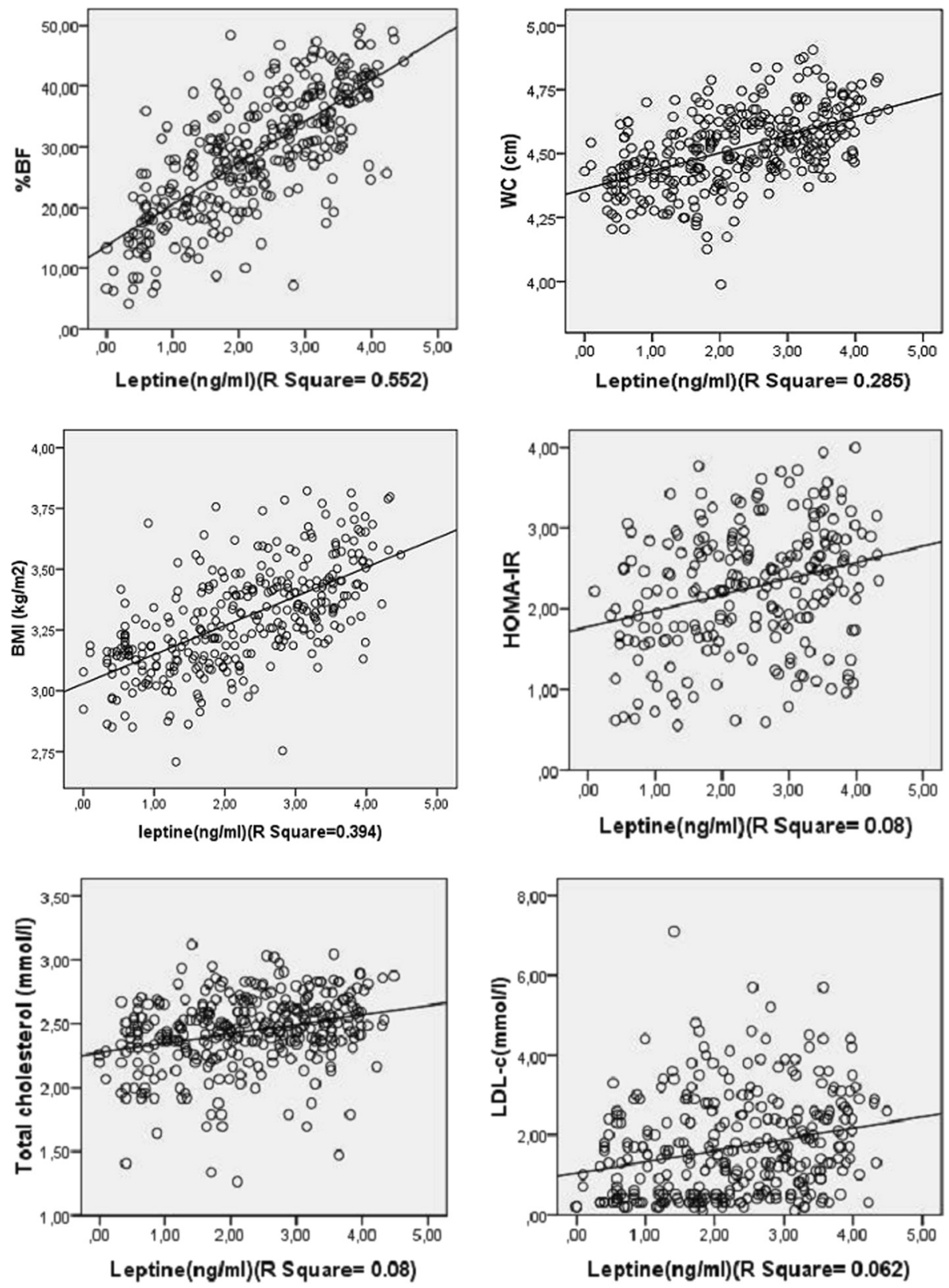

Fig. 3 Linear regression presenting the associations of leptin with BMI, WC, \%BF, total-cholesterol, LDL-cholesterol and HOMA-IR

studies suggest that the high molecular weight type of adiponectin is biologically active.

\section{Conclusions}

This study confirms the associations previously observed between adiponectin and leptin, and obesity, blood lipids and insulin resistance. Adiponectin is associated with reduced adiposity, especially abdominal adiposity, improved insulin sensitivity and lower levels of pro-atherogenic blood lipoproteins.
In spite of the interactions $\mathrm{BF} \%$ and HOMA-IR with gender in their association to adiponectin, adiponectin is thus suggested to be a predictor of good metabolic and cardiovascular health in this sub-Saharan African population. Contrariwise, leptin is strongly associated to anthropometric indexes of obesity (BMI, WC, WHR, BF\%) and obesity-related adverse effects that trigger cardiovascular disease, including insulin resistance for the first time in an African population, increased blood pressure and 
pro-atherogenic blood lipids. The associations of HOMA-IR, BMI and WC with leptin were related to gender in this population.

\section{Ethics approval and consent to participate}

The authors attest that the present study was approved by the National Ethics Committee for Human Health Research and by the Ministry of Public Health of Cameroon. Written informed consent was obtained from all participants.

\section{Abbreviations}

AMPK: AMP-activated protein kinase; BF\%: percent body fat; BMI: body mass index; HDL-c: high-density lipoprotein -cholesterol; HMW: high molecular weight; HOMA-IR: homeostasis model for assessment of insulin resistance; LDL-c: low-density lipoprotein -cholesterol; PPARa: peroxisome proliferatoractivated receptor gamma; TC: total cholesterol; TG: triglycerides; WC: waist circumference (WC); WHR: waist-to-hip ratio.

\section{Competing interests}

The authors declare that they have no competing interests.

\section{Authors' contributions}

Study conception and design: CNAA, PB, LSEN, JFG, JCM, ES. Data collection: CNAA, PB, ES. Statistical analysis and interpretation: CNAA, JJNN. Drafting: JJNN, CNAA. Critical discussion and manuscript revision: CNAA, JJNN, MKN, ES, PB, LSEN, JCM , JFG. All authors approved the final version of the manuscript.

\section{Acknowledgements}

We are grateful to all the volunteers who participated in the study.

\section{Funding}

This study was funded by the Service of Action and Cooperation of the French embassy in Cameroon.

\section{Author details \\ ${ }^{1}$ Department of Animal Science, Faculty of Science, University of Douala, Douala, Cameroon. ${ }^{2}$ Department of Medicine, Groote Schuur Hospital and University of Cape Town, Cape Town, South Africa. ${ }^{3}$ Medical Diagnostic Center, Yaounde, Cameroon. ${ }^{4}$ Department of Animal Science, Higher Teacher's Training College, University of Yaoundé I, Yaounde, Cameroon. ${ }^{5}$ Department of Hormonal Biology, Saint-Louis Hospital, Public Assistance - Paris Hospitals, University Paris-Diderot Paris-7, Paris, France. ${ }^{6}$ Department of Diabetes and Endocrinology, Lariboisiere Hospital, Public Assistance - Paris Hospitals, University Paris-Diderot Paris-7, Paris, France. " INSERM UMRS 1138, Cordeliers Research Centre, University Pierre et Marie Curie-Paris 6, Paris, France. ${ }^{8}$ Department of Internal Medicine and Specialties, Faculty of Medicine and Biomedical Science, University of Yaoundé I, Yaounde, Cameroon. ' Laboratory for Molecular Medicine and Metabolism, Biotechnology Center, University of Yaoundé I, Yaounde, Cameroon. \\ ${ }^{10}$ National Obesity Center, Yaoundé Central Hospital, Yaounde, Cameroon.}

Received: 18 August 2015 Accepted: 9 May 2016

Published online: 17 May 2016

\section{References}

1. Ng M, Fleming T, Robinson M, Thomson B, Graetz N, Margono C, et al. Global, regional, and national prevalence of overweight and obesity in children and adults during 1980-2013: a systematic analysis for the Global Burden of Disease Study 2013. Lancet. 2014;384(9945):766-81.

2. Li Y, Ding L, Hassan W, Abdelkader D, Shang J. Adipokines and hepatic insulin resistance. J Diabetes Res. 2013;2013:170532.

3. Ahima RS, Flier JS. Adipose tissue as an endocrine organ. Trends Endocrinol Metab. 2000;11(8):327-32.

4. Li ZY, Wang P, Miao CY. Adipokines in inflammation, insulin resistance and cardiovascular disease. Clin Exp Pharmacol Physiol. 2011;38(12):888-96.
5. Ahima RS. Metabolic actions of adipocyte hormones: focus on adiponectin. Obesity (Silver Spring). 2006;14 Suppl 1:9S-15.

6. Cancello R, Tounian A, Poitou C, Clement K. Adiposity signals, genetic and body weight regulation in humans. Diabetes Metab. 2004;30(3):215-27.

7. Havel PJ. Update on adipocyte hormones: regulation of energy balance and carbohydrate/lipid metabolism. Diabetes. 2004;53 Suppl 1:S143-51.

8. Oda N, Imamura S, Fujita T, Uchida Y, Inagaki K, Kakizawa H, et al. The ratio of leptin to adiponectin can be used as an index of insulin resistance. Metabolism. 2008;57(2):268-73.

9. Zaletel J, Barlovic DP, Prezelj J. Adiponectin-leptin ratio: a useful estimate of insulin resistance in patients with Type 2 diabetes. Endocrinol Invest. 2010;33(8):514-8.

10. Zhuo Q, Wang Z, Fu P, Piao J, Tian Y, Xu J, et al. Comparison of adiponectin, leptin and leptin to adiponectin ratio as diagnostic marker for metabolic syndrome in older adults of Chinese major cities. Diabetes Res Clin Pract. 2009;84(1):27-33.

11. Takamura N, Hayashida N, Hagane K, Kadota K, Yamasaki H, Abiru N, et al. Leptin to high-molecular-weight adiponectin ratio is independently correlated with carotid intima-media thickness in men, but not in women. Biomarkers. 2010;15(4):340-4.

12. Lim CC, Teo BW, Tai ES, Lim SC, Chan CM, Sethi S, et al. Elevated serum leptin, adiponectin and leptin to adiponectin ratio is associated with chronic kidney disease in asian adults. PLoS One. 2015;10(3):e0122009.

13. Wang $Y$, Lam KS, Yau MH, Xu A. Post-translational modifications of adiponectin: mechanisms and functional implications. Biochem J. 2008:409(3):623-33.

14. Xu A, Chan KW, Hoo RL, Wang Y, Tan KC, Zhang J, et al. Testosterone selectively reduces the high molecular weight form of adiponectin by inhibiting its secretion from adipocytes. J Biol Chem. 2005;280(18):18073-80.

15. Antuna-Puente B, Feve B, Fellahi S, Bastard JP. Adipokines: the missing link between insulin resistance and obesity. Diabetes Metab. 2008;34(1):2-11.

16. Scheer FA, Chan JL, Fargnoli J, Chamberland J, Arampatzi K, Shea SA, et al Day/night variations of high-molecular-weight adiponectin and lipocalin-2 in healthy men studied under fed and fasted conditions. Diabetologia. 2010; 53(11):2401-5

17. Gavrila A, Peng CK, Chan JL, Mietus JE, Goldberger AL, Mantzoros CS. Diurnal and ultradian dynamics of serum adiponectin in healthy men: comparison with leptin, circulating soluble leptin receptor, and cortisol patterns. J Clin Endocrinol Metab. 2003;88(6):2838-43.

18. Araneta MR, Barrett-Connor E. Adiponectin and ghrelin levels and body size in normoglycemic Filipino, African-American, and white women. Obesity (Silver Spring). 2007;15(10):2454-62.

19. Hulver MW, Saleh O, MacDonald KG, Pories WJ, Barakat HA. Ethnic differences in adiponectin levels. Metabolism. 2004;53(1):1-3.

20. Kim CX, Bailey KR, Klee GG, Ellington AA, Liu G, Mosley Jr TH, et al. Sex and ethnic differences in 47 candidate proteomic markers of cardiovascular disease: the Mayo Clinic proteomic markers of arteriosclerosis study. PLoS One. 2010;5(2):e9065.

21. Schutte AE, Huisman HW, Schutte R, Malan L, van Rooyen JM, Malan NT, et al. Differences and similarities regarding adiponectin investigated in African and Caucasian women. Eur J Endocrinol. 2007;157(2):181-8.

22. Meilleur KG, Doumatey A, Huang H, Charles B, Chen G, Zhou J, et al. Circulating adiponectin is associated with obesity and serum lipids in West Africans. J Clin Endocrinol Metab. 2010;95(7):3517-21.

23. Doumatey AP, Zhou J, Huang $H$, Adeleye J, Balogun W, Fasanmade $\mathrm{O}$, et al. Circulating adiponectin is associated with renal function independent of age and serum lipids in west africans. Int J Nephrol. 2012;2012:730920.

24. Ntyintyane L, Panz V, Raal FJ, Gill G. Leptin, adiponectin, and high-sensitivity C-reactive protein in relation to the metabolic syndrome in urban South African blacks with and without coronary artery disease. Metab Syndr Relat Disord. 2009;7(3):243-8.

25. Friedewald WT, Levy RI, Fredrickson DS. Estimation of the concentration of low-density lipoprotein cholesterol in plasma, without use of the preparative ultracentrifuge. Clin Chem. 1972;18(6):499-502.

26. Organization WH. Obesity: preventing and managing the global epidemic: World Health Organization. 2000.

27. Consultation WE. Waist circumference and waist-hip ratio. 2011

28. Okorodudu DO, Jumean MF, Montori VM, Romero-Corral A, Somers VK, Erwin PJ, et al. Diagnostic performance of body mass index to identify obesity as defined by body adiposity: a systematic review and metaanalysis. Int J Obes (Lond). 2010;34(5):791-9. 
29. Guerre-Millo M. Adipose tissue and adipokines: for better or worse. Diabetes Metab. 2004;30(1):13-9.

30. Nigro E, Scudiero O, Monaco ML, Palmieri A, Mazzarella G, Costagliola C, et al. New insight into adiponectin role in obesity and obesity-related diseases. Biomed Res Int. 2014;2014:658913.

31. Caselli C. Role of adiponectin system in insulin resistance. Mol Genet Metab. 2014;113(3):155-60.

32. Cnop M, Havel PJ, Utzschneider KM, Carr DB, Sinha MK, Boyko EJ, et al. Relationship of adiponectin to body fat distribution, insulin sensitivity and plasma lipoproteins: evidence for independent roles of age and sex. Diabetologia. 2003;46(4):459-69.

33. Arita Y, Kihara S, Ouchi N, Takahashi M, Maeda K, Miyagawa J, et al. Paradoxical decrease of an adipose-specific protein, adiponectin, in obesity. Biochem Biophys Res Commun. 1999;257(1):79-83.

34. Weyer C, Funahashi T, Tanaka S, Hotta K, Matsuzawa Y, Pratley RE, et al. Hypoadiponectinemia in obesity and type 2 diabetes: close association with insulin resistance and hyperinsulinemia. J Clin Endocrinol Metab. 2001;86(5):1930-5.

35. Rasmussen-Torvik $\sqcup$, Wassel CL, Ding J, Carr J, Cushman M, Jenny N, et al. Associations of body mass index and insulin resistance with leptin, adiponectin, and the leptin-to-adiponectin ratio across ethnic groups: the Multi-Ethnic Study of Atherosclerosis (MESA). Ann Epidemiol. 2012;22(10):705-9.

36. Sobngwi E, Effoe $V$, Boudou P, Njamen D, Gautier JF, Mbanya JC. Waist circumference does not predict circulating adiponectin levels in subSaharan women. Cardiovasc Diabetol. 2007;6:31

37. Cote M, Mauriege P, Bergeron J, Almeras N, Tremblay A, Lemieux I, et al. Adiponectinemia in visceral obesity: impact on glucose tolerance and plasma lipoprotein and lipid levels in men. J Clin Endocrinol Metab. 2005; 90(3):1434-9.

38. Després J-P. Abdominal obesity: the most prevalent cause of the metabolic syndrome and related cardiometabolic risk. Eur Heart J Suppl. 2006;8(suppl B):B4-12

39. Motoshima H, Wu X, Sinha MK, Hardy VE, Rosato EL, Barbot DJ, et al. Differential regulation of adiponectin secretion from cultured human omental and subcutaneous adipocytes: effects of insulin and rosiglitazone. J Clin Endocrinol Metab. 2002;87(12):5662-7.

40. Perry AC, Applegate EB, Jackson ML, Deprima S, Goldberg RB, Ross R, et al. Racial differences in visceral adipose tissue but not anthropometric markers of health-related variables. J Appl Physiol (1985). 2000;89(2):636-43.

41. Bonneau GA, Pedrozo WR, Berg G. Adiponectin and waist circumference as predictors of insulin-resistance in women. Diabetes Metab Syndr. 2014;8(1):3-7.

42. Ding YS, Guo SX, Ma RL, Li SG, Guo H, Zhang JY, et al. Association of Metabolic Syndrome with the Adiponectin to Homeostasis Model Assessment of Insulin Resistance Ratio. Mediators Inflamm. 2015;2015: 607364.

43. Gao H, Fall T, van Dam RM, Flyvbjerg A, Zethelius B, Ingelsson E, et al. Evidence of a causal relationship between adiponectin levels and insulin sensitivity: a Mendelian randomization study. Diabetes. 2013;62(4):1338-44.

44. Rajkovic N, Zamaklar M, Lalic K, Jotic A, Lukic L, Milicic T, et al. Relationship between obesity, adipocytokines and inflammatory markers in type 2 diabetes: relevance for cardiovascular risk prevention. Int J Environ Res Public Health. 2014;11(4):4049-65.

45. Kadowaki T, Yamauchi T, Kubota N, Hara K, Ueki K, Tobe K. Adiponectin and adiponectin receptors in insulin resistance, diabetes, and the metabolic syndrome. J Clin Invest. 2006;116(7):1784-92.

46. Kadowaki T, Yamauchi T. Adiponectin and adiponectin receptors. Endocr Rev. 2005;26(3):439-51.

47. Li S, Shin HJ, Ding EL, van Dam RM. Adiponectin levels and risk of type 2 diabetes: a systematic review and meta-analysis. JAMA. 2009;302(2):179-88.

48. Sato $H$, Ishikawa $M$, Sugai $H$, Funaki A, Kimura $Y$, Sumitomo M, et al. Sex hormones influence expression and function of peroxisome proliferatoractivated receptor gamma in adipocytes: pathophysiological aspects. Horm Mol Biol Clin Investig. 2014;20(2):51-61.

49. Kamon J, Yamauchi T, Terauchi Y, Kubota N, Kadowaki T. The mechanisms by which PPARgamma and adiponectin regulate glucose and lipid metabolism. Nihon Yakurigaku Zasshi. 2003;122(4):294-300.

50. Yamauchi T, Kamon J, Minokoshi Y, Ito Y, Waki H, Uchida S, et al. Adiponectin stimulates glucose utilization and fatty-acid oxidation by activating AMP-activated protein kinase. Nat Med. 2002;8(11):1288-95.
51. Yoon MJ, Lee GY, Chung JJ, Ahn YH, Hong SH, Kim JB. Adiponectin increases fatty acid oxidation in skeletal muscle cells by sequential activation of AMP-activated protein kinase, p38 mitogen-activated protein kinase, and peroxisome proliferator-activated receptor alpha. Diabetes. 2006; 55(9):2562-70.

52. Goldstein BJ, Scalia RG, Ma XL. Protective vascular and myocardial effects of adiponectin. Nat Clin Pract Cardiovasc Med. 2009;6(1):27-35.

53. Stefanovic A, Kotur-Stevuljevic J, Spasic S, Bogavac-Stanojevic N, Bujisic N. The influence of obesity on the oxidative stress status and the concentration of leptin in type 2 diabetes mellitus patients. Diabetes Res Clin Pract. 2008;79(1):156-63.

54. Abdella NA, Mojiminiyi OA, Moussa MA, Zaki M, Al Mohammedi H, Al Ozairi ES, et al. Plasma leptin concentration in patients with Type 2 diabetes: relationship to cardiovascular disease risk factors and insulin resistance. Diabet Med. 2005:22(3):278-85.

55. Kaplon-Cieslicka A, Postula M, Rosiak M, Peller M, Kondracka A, Serafin A, et al. Association of adipokines and inflammatory markers with lipid control in type 2 diabetes. Pol Arch Med Wewn. 2015;125(6):414-23.

56. Uslu S, Kebapci N, Kara M, Bal C. Relationship between adipocytokines and cardiovascular risk factors in patients with type 2 diabetes mellitus. Exp Ther Med. 2012:4(1):113-20.

\section{Submit your next manuscript to BioMed Central and we will help you at every step:}

- We accept pre-submission inquiries

- Our selector tool helps you to find the most relevant journal

- We provide round the clock customer support

- Convenient online submission

- Thorough peer review

- Inclusion in PubMed and all major indexing services

- Maximum visibility for your research

Submit your manuscript at www.biomedcentral.com/submit
C Biomed Central 